\title{
Kinetics of meiosis in azoospermic males: a joint histological and cytological approach
}

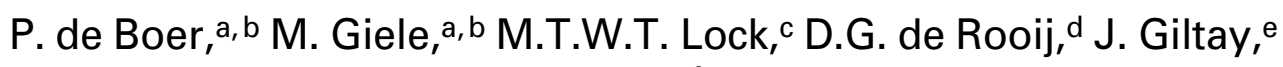 \\ R. Hochstenbach, ${ }^{e}$ and E.R. te Velde ${ }^{f}$ \\ ${ }^{a}$ Laboratory of Genetics, Wageningen Institute of Animal Sciences, ZODIAC, Wageningen; \\ ${ }^{b}$ Department of Obstetrics and Gynaecology, UMC St Radboud, Nijmegen; \\ c Department of Urology, University Medical Centre Utrecht; \\ ${ }^{\mathrm{d}}$ Department of Endocrinology, Faculty of Biology, Utrecht University; \\ Departments of ${ }^{\mathrm{e}}$ Biomedical Genetics and ${ }^{\mathrm{f}}$ Obstetrics, Neonatology and Gynaecology, University Medical Centre Utrecht, \\ Utrecht (The Netherlands)
}

\begin{abstract}
We have developed a protocol for the identification of aberrant chromosome behavior during human male meiosis up to metaphase of the secondary spermatocyte. Histological evaluation by the Johnsen score of a testicular biopsy was combined with immunofluorescence of first meiotic prophase spermatocytes, using antibodies against synaptonemal complex protein 3 (SYCP3) and the product of the ataxia telangiectasia and rad3-related gene (ATR). This combination enables accurate meiotic prophase substaging and the identification of pachytene spermatocytes with asynapsis. Furthermore, we also investigated the competence of late pachytene primary spermatocytes to complete the first meiotic division up to metaphase and of secondary spermatocytes to transform into metaphase by an in vitro challenge with okadaic acid (OA). We tested this protocol on five males with normal Johnsen scores that presented with obstructive azoospermia, five males with low Johnsen scores and non-obstructive azoospermia and six vasectomized control males of proven fertility and normal Johnsen scores. In all azoospermics, the profiling of meiotic
\end{abstract}

prophase stages by immunofluorescence increases the resolving power of the Johnsen score. In both obstructive and nonobstructive azoospermic patients, relatively more leptotene meiotic prophase stages were counted compared to the controls. In non-obstructive azoospermics, a marked heterogeneity in spermatogenesis was found, after combining the results of all three approaches, pointing at functional mosaicism of the germinal epithelium. Asynaptic pachytene spermatocytes were rarely encountered. Also, when first meiotic metaphase could be induced by OA, chiasma counts were normal. In none of the non-obstructive azoospermic males did the pattern of spermatogenesis resemble that of knock-out mouse azoospermics. We conclude that this combined histological and cytological approach enables a detailed phenotypic classification of infertile males, at a level comparable to that applied for male-sterile knock-out mice with a meiotic defect. This may facilitate the identification of candidate genes for human male infertility.

Copyright $(2003$ S. Karger AG, Basel
The advent of artificial reproduction techniques (Silber, 1998) for the treatment of male factor infertility has raised interest into the study of the causes of impaired spermatogenesis in man. Of all infertile marriages, estimated at $10-15 \%$ of total, about half include male factor etiology (Hull et al., 1985; ESHRE Capri Workshop, 1996). In about $60 \%$ of azoospermic

\footnotetext{
Received 25 September 2003; manuscript accepted 27 November 2003.

Request reprints from: P. de Boer, Dept. of Obstetrics and Gynaecology UMC St Radboud, Obgyn 415, P.O. Box 9101

6500 HB Nijmegen (The Netherlands); telephone: +31 243610869/3557 fax: +31 243616375; e-mail: P.deBoer@obgyn.umcn.nl
}

males, an obvious clinical reason, such as an obstruction in the efferent ducts, cannot be found (Westlander et al., 1999). For this group, the diagnosis idiopathic male infertility is coined, unless a genetic factor such as deletions of the azoospermia factors (AZF) on the Y chromosome (15-20\% in azoospermic probands and $7-10 \%$ in severe oligozoospermia, Krausz et al., 2000) or an abnormal karyotype (4-12\%, de Braekeleer and Dao, 1991; Tuerlings et al., 1998) can be identified. Based on the comparative analysis of the genetics of male sterility in Drosophila, mouse and man, Hackstein et al. (2000) argue that most cases of idiopathic male infertility in man are due to autosomal recessive mutations. Support for this view comes from family studies (Lilford et al., 1994; Meschede et al., 2000)

\footnotetext{
KARGER Fax +41613061234 E-mail karger@karger.ch www.karger.com

(C) 2004 S. Karger AG, Basel 0301-0171/04/1051-0036\$21.00/0
}

Accessible online at: www. karger.com/cgr 
and from the male-sterile phenotypes of numerous homozygous recessive gene knock-outs in the mouse (Escalier, 2001; TBASE, http://www.jax.org/tbase).

The identification of candidate genes for human male infertility could be guided by the careful phenotypic comparison with well-characterized male-sterile mutants in the mouse (Hackstein et al., 2000). Such (knock-out) mutants are characterized in great detail using standard histological techniques combined with immunofluorescence of meiotic and postmeiotic spermatogenic stages (de Vries et al., 1999). For humans, the introduction of the Johnsen score (Johnsen, 1970) for the quantification of spermatogenesis per tubular cross-section has greatly helped in the histological classification of testicular biopsies in cases of idiopathic male infertility. However, a histological analysis alone does not allow an unequivocal distinction between hypospermatogenesis (i.e. all stages of spermatogenesis present but at a diminished density) and maturation arrest irrespective of the stage of spermatogenesis (but often during meiotic prophase) (Levin, 1979). Moreover, in both mouse and man, the transitions between leptotene, zygotene and early pachytene stages of first meiotic prophase cannot be distinguished by histological examination of a tubular crosssection. This is also true for the division between early, mid and to a lesser extent late pachytene. Moreover, all these stages are more difficult to identify in man because one tubular crosssection can contain several meiotic stages (Hilscher, 1999; B. Hilscher, personal communication).

Here we describe a protocol that supplements the Johnsen score by adding a detailed cytological analysis of the first meiotic prophase in an adjacent testicular biopsy. The distinction between leptotene, early, mid and late zygotene and early, mid and late pachytene was made by immunofluorescence (IF), using a polyclonal antibody that predominantly stains the $\mathrm{Mr}$ 30,000-33,000 synaptonemal complex protein 3 (SYCP3) in the axial and lateral elements of the synaptonemal complex (SC, Offenberg et al., 1991), in combination with a monoclonal antibody raised against the product of the Atr gene (ataxia telangiectasia and rad3-related, Keegan et al., 1996). Anti-Atr specifically recognizes the axial elements of homologous chromosomes when formation of the SC is delayed or has failed (asynapsis, Moens et al., 1999; Baart et al., 2000). Consequently, the axial elements of the unsynapsed portions of the $\mathrm{X}$ and $\mathrm{Y}$ chromosomes in the sex vesicle and the surrounding chromatin are stained as well, allowing a clear distinction between late zygotene and early pachytene (Baart et al., 2000). To verify the occurrence of crossing-over, a functional cytological test was introduced. Short in vitro incubation of spermatogenic cells with the phosphatase 1 and 2 a inhibitor okadaic acid (OA) specifically drives late pachytene primary spermatocytes that have completed chromosome synapsis and that have passed the pachytene checkpoint (Cobb et al., 1999; Tung et al., 2000) into diakinesis/metaphase of the first meiotic division (Wiltshire et al., 1995). Also, the reserve of secondary spermatocytes is visualized by the appearance of meiotic metaphase II. Using this method, the fraction of spermatocytes can be estimated that is capable of completing first meiotic prophase. In addition, the autosome and sex chromosome chiasma counts can be determined.
We have tested this protocol of combined investigations on five probands with obstructive azoospermia, and on five probands with non-obstructive azoospermia. Six men of proven fertility who presented for a reconstruction of the vas deferens after a previous vasectomy served as controls.

\section{Materials and methods}

\section{Patients}

All probands were recruited at the urology and IVF clinics of the University Medical Centre Utrecht. Six men that requested a refertilization operation after a previous vasectomy (average age $43.5 \pm 3.2$ years) served as controls with biopsies taken at the operation. Four of these had adult children and one fathered a child afterwards. From one man no data were available. The average time between vasectomy and reconstruction of the vas deferens was 9 years (range 5-15 years). Nine azoospermic probands and a severely oligozoospermic one, who had a sperm count of $4.0 \times 10^{6} / \mathrm{ml}$ and was diagnosed with oligoasthenoteratozoospermia (OAT), agreed to have a biopsy taken for further diagnosis of their infertility. The average age of the infertile patients was $30.5 \pm 2.5$ years. A detailed patient and family history was taken with special emphasis on familial infertility and parental consanguinity. Routine clinical investigation included checking for presence of a varicocele, palpation of vas deferens, epididymis and testis (turgor). Scrotal ultrasound was recorded and an assessment of testicular volume was made. Serum concentrations of luteinizing hormone (LH) and follicle stimulating hormone (FSH) were measured by immunometric assays on the fully automated ACS-Centaur immunoassay platform (Bayer Diagnostics). Inter-assay variation coefficients for $\mathrm{LH}$ were $4.8,4.5$ and $5.8 \%$ at $4.5,18.7$ and $38.5 \mathrm{IU} / 1$, respectively. A concentration above $6.0 \mathrm{IU} / 1$ was considered abnormal. For FSH the inter-assay variation was $6.7,7.5$ and $4.6 \%$ at $9.0,25.8$ and $63.5 \mathrm{IU} / 1$, respectively, with a concentration above $8.0 \mathrm{IU} / \mathrm{l}$ being abnormal. Standardization was against the WHO 80/552 reference material for LH and the WHO 94/632 reference for FSH. Testosterone was measured by a radioimmunoassay following extraction. Inter-assay variation was 9.6, 6.8 and $8.2 \%$ at concentrations of $0.83,2.5$ and $11 \mathrm{nmol} / 1$, respectively. A concentration below $15 \mathrm{nmol} / \mathrm{l}$ was considered abnormal. Peripheral blood was also taken for karyotyping, DNA analysis of AZF deletions (Kremer et al., 1997) and, in case of absence of the vas deferens, mutation analysis of the CFTR gene (Eggerding et al., 1995). This project received approval of the ethics committee of the University Medical Centre Utrecht (number 97/177).

\section{Histology and cytology}

Biopsy material was obtained under general anesthesia. Two adjacent testicular biopsies were taken left and right, measuring approximately $7 \times 7 \times$ $7 \mathrm{~mm}$ each. One biopsy per side was used for routine histological processing. Histological evaluation by the Johnsen score was based on 40 cross-sections of seminiferous tubules per testis (Johnsen, 1970). The other two biopsies were collected in MEM alpha medium (Life technologies/GIBCO), pooled and macerated within $25 \mathrm{~min}$ after collection in a small drop of medium, using two ribbed, curved forceps. Cells were washed once in the same medium and the cell suspension was divided for the following three purposes: i) investigation of first meiotic prophase in sedimented, 2-dimensional nuclei by IF, ii) the same, but now in 3-dimensional nuclei embedded in a fibrin clot, and iii) investigation of the competence of spermatocytes to complete first and second meiotic prophase by OA stimulation in vitro.

\section{Sedimentation spreading of meiotic prophase spermatocytes}

The procedure followed the technique of Peters et al. (1997) with some slight modifications. A final suspension was made in $100 \mathrm{mM}$ sucrose at a cell concentration of between 15 and $25 \times 10^{6}$ cells $/ \mathrm{ml}$. A pre-cleaned slide was dipped in a $1 \%$ paraformaldehyde solution at $\mathrm{pH} 9.2$ containing $0.15 \%$ Triton X-100. Before applying the cell suspension to the wetted slide, $10 \mu \mathrm{l}$ cell suspension was mixed with $10 \mu \mathrm{l} 0.003 \%$ lipsol solution for improved immunoreactivity. Slides were kept horizontally and cells were allowed to sediment for $1 \mathrm{~h}$ in a closed humidified box. Thereafter, the slides were carefully rinsed with $0.08 \%$ photoflo (Kodak) and air-dried. Cells were stored in closed containers at a temperature of $-80^{\circ} \mathrm{C}$ and were used for IF within 6 months. 

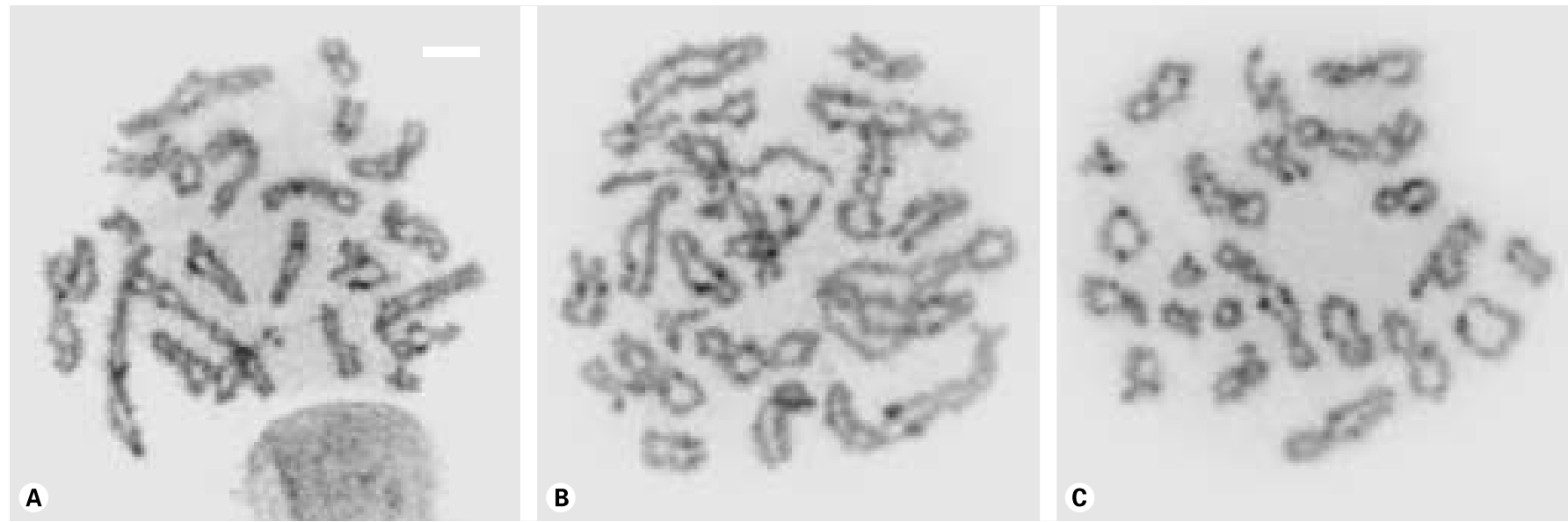

Fig. 1. Spiralization of bivalents following incubation with $\mathrm{OA}$ in a male of proven fertility (Class I). (A-C) Increasing contraction of the chromosomes. The bar represents $4 \mu \mathrm{m}$.

Embedding of meiotic prophase spermatocytes in fibrin clots

The technique of Hunt et al. (1995) was used as described by Baart et al. (2000). Fixed, fibrin-embedded cells can be kept at $4^{\circ} \mathrm{C}$ in PBS with $10 \%$ newborn goat serum for maximally one month. Alternatively, cells can be stored at $-80^{\circ} \mathrm{C}$ in a medium consisting of $20 \% \mathrm{FCS}, 5 \% \mathrm{DMSO}$ and $10 \%$ glycerol supplemented with PBS. Slides were immersed in the medium and inserted in a container insulated with isopropanol for $20 \mathrm{~min}$ at $-20^{\circ} \mathrm{C}$ before storage at $-80^{\circ} \mathrm{C}$. Cell samples can be maintained for at least one year before immunoreactivity is markedly reduced.

\section{Okadaic acid challenge}

Spermatocytes were incubated for $5 \mathrm{~h}$ in $800 \mu \mathrm{l}$ cultures at a cell concentration of $2 \times 10^{6}$ cells $/ \mathrm{ml}$ in complete MEM alpha medium at $32^{\circ} \mathrm{C}$ in an atmosphere containing $5 \% \mathrm{CO}_{2}$. The complete MEM alpha medium (O'Brien, 1987) contained $6 \%$ fetal calf serum (BioWhittaker), $1 \mathrm{mM}$ sodium pyruvate, $0.13 \%(w / v)$ of a $50 \%$ sodium lactate solution, $1 \mathrm{mM}$ glutamin, $21 \mathrm{mM}$ Hepes and $0.01 \%(w / v)$ gentamycin. Okadaic acid (Sigma, from a stock of $240 \mu \mathrm{M}$ in ethanol) was added to a final concentration of $2 \mu \mathrm{M}$. Harvesting of cells essentially followed the procedure of Evans et al. (1964). The slides were stained for constitutive heterochromatin using the method of Chandley and Fletcher (1973) with minor modifications: slides were aged for one night at $37^{\circ} \mathrm{C}$, heated for $5 \mathrm{~min}$ at $100^{\circ} \mathrm{C}$ and hydrolyzed for $1 \mathrm{~min}$ in $0.1 \mathrm{M} \mathrm{HCl}$ before treatment with $4 \% \mathrm{Ba}(\mathrm{OH})_{2}$ for $15 \mathrm{~s}$ at $37^{\circ} \mathrm{C}$. Staining was for $1 \mathrm{~h}$ with a solution of $10 \%$ Giemsa (Merck) in Gurr's buffer tablets pH 6.8.

About 50 round spermatogenic cells including spermatogonial metaphases, first meiotic pachytene stages with (MI) and without contracting bivalents and secondary spermatocytes showing chromosome spiralization (MII) were identified per male. Frequencies of MI and MII spermatocytes were calculated on this basis. Round spermatids, spermatogonial interphases and early primary spermatocytes were excluded. The number of spermatozoa (and similar nuclei without a tail) was recorded for the same fields. Primary spermatocytes in a diakinesis-like stage (Fig. 1) were used for checking on autosomal and gonosomal univalents and for determination of chiasma counts. Control patient 2 did not yield a result due to a technical error.

\section{Immunofluorescence}

For IF on sedimented and embedded meiotic prophase cells the protocol of Baart et al. (2000) was followed. Axial elements and lateral elements of the SC were immunostained with a rabbit polyclonal serum 175 , elicited against isolated rat SCs (Offenberg et al., 1991). This antiserum predominantly recognizes the Mr 30,000-33,000 synaptonemal complex protein 3 (SYCP3) and was diluted $1: 1,000$ to $1: 1,500$. FITC-labeled swine anti-rabbit (Monosan/Sanbio PS 117F, 1:100) was used as a secondary antibody. A monoclonal antibody (224C) against the kinase domain of the product of the Atr gene (ataxia telangiectasia and rad3-related) (Keegan et al., 1996 and Keegan, personal communication) was applied in a dilution of 1:250, and detected with goat anti-mouse IgG conjugated with Texas red (Molecular Probes, Alexa 594 Goat anti-mouse, no. A-11005, 1:100). We noticed that the variation in the spectrum of stages between control patients and between repeated observations in one particular control patient was less in fibrin-encapsulated nuclei than in sedimented nuclei (data not shown), and also that anti-ATR staining was more robust in embedded nuclei, as in the mouse (Baart et al., 2000). Therefore, meiotic prophase stages and substages were scored in embedded nuclei. About 100 nuclei were scored for each male.

\section{Results}

\section{Definition of patient groups}

A survey of the Johnsen scores and endocrine parameters is given in Table 1. Two CFTR mutations were found (see below). AZF deletions and karyotypic abnormalities were not found. We subdivided the probands in three classes according to the following criteria:

Class I: Vasectomized males of proven fertility with a wish to regain fertility (control males, 1-6);

Class II: Obstructive azoospermic/severely oligozoospermic males (7-11);

Class III: Non-obstructive azoospermic males (12-16).

\section{Definition of meiotic prophase (sub)stages by immunofluorescence}

Immunofluorescence using anti-SYCP3 and anti-ATR enabled the efficient characterization of leptotene, zygotene, pachytene and diplotene first meiotic prophase stages in males of proven fertility. Nuclei with no apposition of axial elements were classified as leptotene (Fig. 2A). Zygotene was divided in early (Fig. 2B), mid (Fig. 2C) and late (Fig. 2D) substages, as deduced from the relative progress of SC formation. During early zygotene, pairing of homologous chromosomes was limited to telomeric regions (Fig. 2B). During late zygotene, the unsynapsed segments of homologous chromosomes are only in interstitial segments (Fig. 2D), with intermediate configurations in mid zygotene (Fig. 2C). Nuclei showing complete axial apposition of the autosomes were termed pachytene. In addi- 

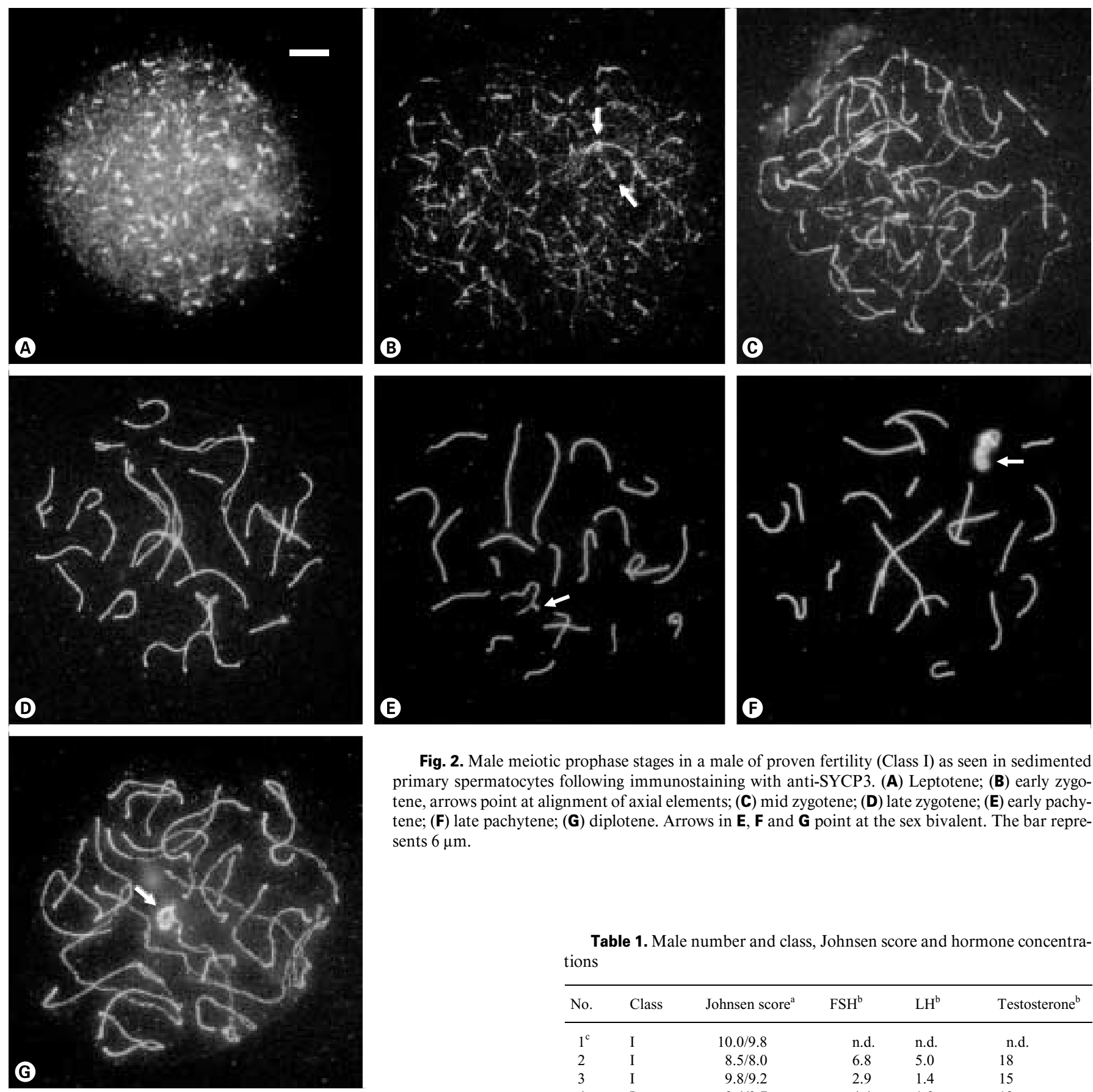

Fig. 2. Male meiotic prophase stages in a male of proven fertility (Class I) as seen in sedimented primary spermatocytes following immunostaining with anti-SYCP3. (A) Leptotene; (B) early zygotene, arrows point at alignment of axial elements; (C) mid zygotene; (D) late zygotene; (E) early pachytene; (F) late pachytene; (G) diplotene. Arrows in E, $\mathbf{F}$ and $\mathbf{G}$ point at the sex bivalent. The bar represents $6 \mu \mathrm{m}$.

tion, also the conspicuous staining of the sex vesicle by antiATR, appearing at early pachytene, allowed a distinction to be made between late zygotene and early pachytene (Baart et al., 2000). Nomenclature of pachytene substages followed that of Solari (1980) and Chandley et al. (1984) but with limitations because fluorescence microscopy is less able to differentiate between the borders of the substages compared to electron microscopy. Thus, pachytene substages I and II as defined by Chandley et al. (1984) were scored as early (Fig. 2E), substage III was scored as mid, and substages IV and V were scored as

Table 1. Male number and class, Johnsen score and hormone concentrations

\begin{tabular}{cccccc}
\hline No. & Class & Johnsen score $^{\mathrm{a}}$ & FSH $^{\mathrm{b}}$ & LH $^{\mathrm{b}}$ & Testosterone $^{\mathrm{b}}$ \\
\hline $1^{\mathrm{c}}$ & I & $10.0 / 9.8$ & n.d. & n.d. & n.d. \\
2 & I & $8.5 / 8.0$ & 6.8 & 5.0 & 18 \\
3 & I & $9.8 / 9.2$ & 2.9 & 1.4 & 15 \\
4 & I & $9.4 / 9.7$ & 4.4 & 1.9 & 12 \\
5 & I & $9.7 / 9.6$ & 3.7 & 0.9 & 13 \\
6 & I & $9.9 / 9.8$ & 4.0 & 2.7 & 16 \\
7 & II & $9.5 / 9.0$ & 4.0 & 1.6 & 10 \\
8 & II & $9.4 / 9.4$ & 2.1 & 3.4 & 15 \\
9 & II & $9.0 / 9.0$ & 6.5 & 4.7 & 18 \\
10 & II & $7.9 / 9.8$ & 6.9 & 3.6 & 11 \\
11 & II & $8.7 / 9.3$ & 10.0 & 8.7 & 20 \\
12 & III & $3.1 / 3.8$ & 6.0 & 6.0 & 10 \\
13 & III & $4.5 / 4.7$ & 4.1 & 2.5 & 10 \\
14 & III & $2.0 / 2.0$ & 20.6 & 5.3 & 9 \\
15 & III & $3.7 / 2.0$ & 32.0 & 9.0 & 13 \\
16 & III & $3.5 / 3.3$ & 21.9 & 5.3 & 27 \\
\hline
\end{tabular}

a Separate values for biopsies from each testicle are given.

FSH and LH concentrations are in IU/l; testosterone is in nmol/l. Hormone levels were not determined (n.d.) for this patient. 

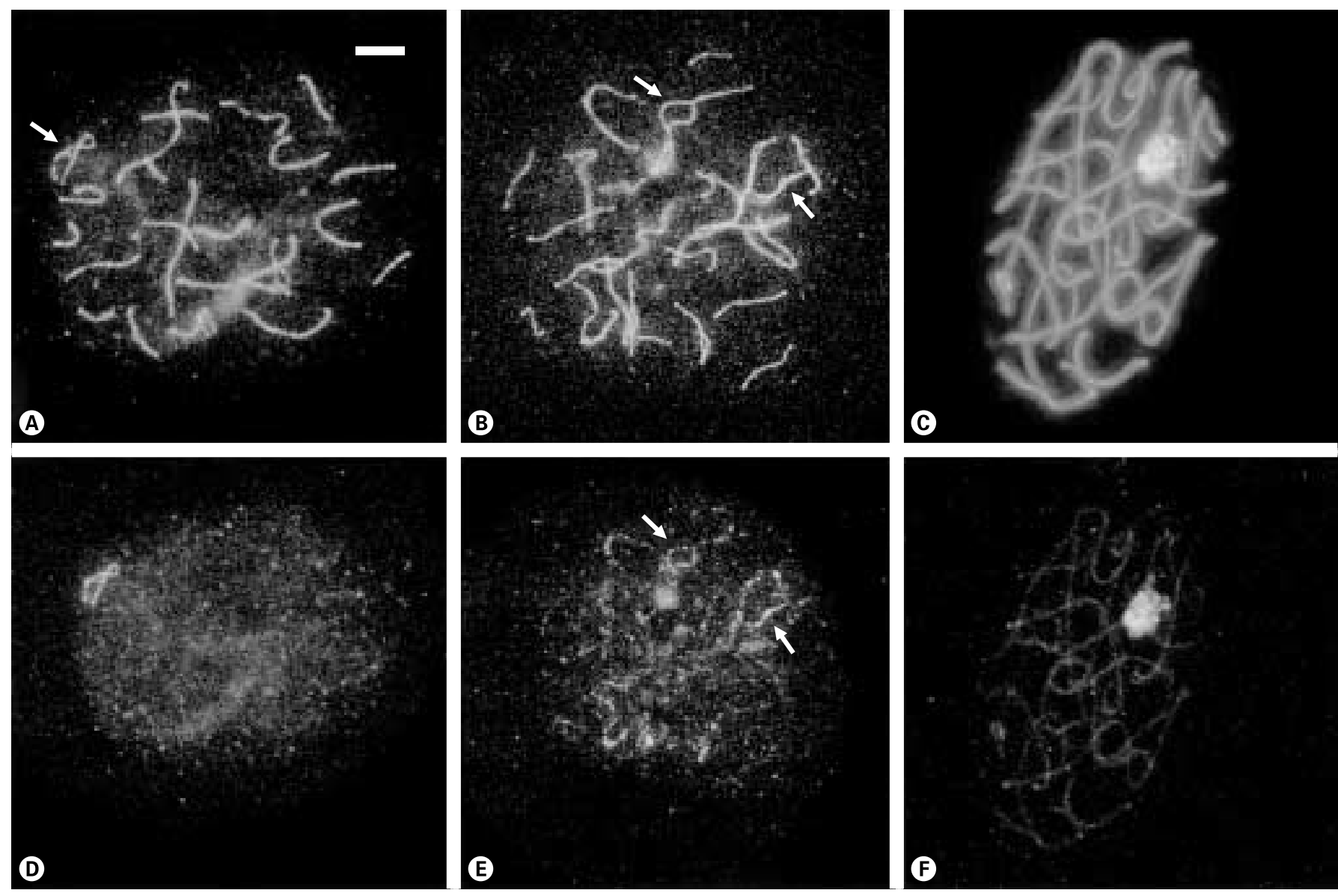

Fig. 3. IF images of first meiotic prophase spermatocytes labeled with anti-SYCP3 (upper panel) and anti- ATR (lower panel). (A, D) Early pachytene with ATR positive axial elements of sex chromosomes (arrow in A). (B, E) Delayed zygotene experiencing synaptic difficulties (arrows in B and E). (C, F) Confocal projection of a late pachytene spermatocyte, showing intense ATR fluorescence of the sex vesicle. The bar represents $6 \mu \mathrm{m}$.

Table 2. Relative frequencies (\%) of zygotene and pachytene substages in control and infertile males

\begin{tabular}{|c|c|c|c|c|c|c|c|c|c|c|c|}
\hline \multirow{2}{*}{$\begin{array}{l}\text { Male } \\
\text { No. }^{a}\end{array}$} & \multirow[t]{2}{*}{ Class } & \multirow{2}{*}{$\begin{array}{l}\text { Leptotene } \\
\text { No. of cells }\end{array}$} & \multicolumn{4}{|l|}{ Zygotene } & \multicolumn{4}{|l|}{ Pachytene } & \multirow{2}{*}{$\begin{array}{l}\text { Total } \\
\text { No. of cells }\end{array}$} \\
\hline & & & No. of cells & early (\%) & $\operatorname{mid}(\%)$ & late $(\%)$ & No. of cells & early (\%) & $\operatorname{mid}(\%)$ & late $(\%)$ & \\
\hline $1-6^{b}$ & I & $57(10 \pm 1 \%)$ & $171(28 \pm 7 \%)$ & $68 \pm 19$ & $18 \pm 8$ & $14 \pm 10$ & $372(68 \pm 5 \%)$ & $33 \pm 8$ & $7 \pm 2$ & $60 \pm 11$ & $600(100 \%)$ \\
\hline 7 & II & 21 & 21 & 52 & 10 & 38 & 58 & 28 & 7 & 65 & 100 \\
\hline 8 & II & 29 & 28 & 46 & 25 & 29 & 43 & 52 & 12 & 36 & 100 \\
\hline 9 & II & 26 & 25 & 44 & 36 & 20 & 49 & 29 & 18 & 53 & 100 \\
\hline 10 & II & 47 & 21 & 58 & 9 & 33 & 32 & 41 & 3 & 56 & 100 \\
\hline 11 & II & 42 & 10 & 50 & 10 & 40 & 48 & 46 & 10 & 44 & 100 \\
\hline 12 & III & 50 & 16 & 75 & 25 & 0 & 34 & 29 & 15 & 56 & 100 \\
\hline 13 & III & 38 & 30 & 70 & 17 & 13 & 32 & 41 & 15 & 44 & 100 \\
\hline a & $\mathrm{st}$ & nt in males & (see text). & & & & & & & & \\
\hline & & & $f$ o & contro & les. & & & & & & \\
\hline
\end{tabular}

late (Fig. 2F). Diplotene was differentiated from late pachytene by the beginning of autosomal desynapsis (Fig. 2G).

The earliest substage at which anti-ATR staining could be observed in fertile males was at early pachytene, with the antibody delineating the axial elements of the sex chromosomes
(Fig. 3A, D). When the formation of the synaptonemal complex was delayed and incomplete, anti-ATR preferentially decorates the axial elements of the non-synapsed chromosome segments (Fig. 3B, E). This phenomenon was rarely observed in control and azoospermic patients. The late pachytene substage could 
also be unequivocally identified by the intense anti-ATR staining of the sex vesicle (Fig. 3C, F).

The results of substaging zygotene and pachytene in embedded spermatocytes are given in Table 2. For the patients with obstructive azoospermia or severe oligozoospermia (Class II), and also for patients 12 and 13 from Class III, the distribution of the zygotene and pachytene meiotic prophase substages was not much different from that in control males, neither was it indicative for an absolute developmental block during meiotic prophase. Within zygotene, Class II males have more late zygotene cells ( $\chi^{2}$ test, $P<0.01$ and $P<0.05$, respectively). The relative frequencies of leptotene, zygotene and pachytene for each male studied are given in Fig. 4, as well as the frequencies of primary and secondary spermatocytes stimulated by OA, and the frequency of sperm nuclei in the same fields.

\section{Sex chromosomal synapsis and chiasmata}

In sedimentation spread preparations from both control and infertile males, early pachytene nuclei were studied for X, Y univalence by lack of adjacent SYCP3-positive SC axial/lateral elements. Neither non-synapsis of the pseudoautosomal regions of the short arms of the sex chromosomes within the sex vesicle nor univalence was seen. Synapsis of the pseudoautosomal regions of the long arm occurred in $19.1 \%$ of meiocytes $(n=131)$ from controls and in $27.5 \%$ of meiocytes $(n=258)$ from infertile males, irrespective of class. Autosomal and gonosomal univalents were also not found in 62 diakinesis spermatocytes, with about equal contributions from control and infertile males. The pattern of chiasmata in the bivalents resembled that reported in the literature (Hultén, 1974).

\section{Clinical evaluation, meiosis and spermatogenesis}

Class I: Vasectomized males of proven fertility $(n=6$, males 1-6). Apart from slightly swollen epididymides, no anatomical abnormalities were found among these males. Male 2 had the lowest Johnsen score in this class (Table 1), with 10\% of tubular cross sections devoid of spermatids on both sides. Quite strikingly, both males 4 and 5 presented with subnormal testosterone levels. From Fig. 4A, showing histograms of the frequencies of first meiotic prophase stages, the average relative duration of leptotene, zygotene and pachytene in control males has been estimated at 10,28 and $62 \%$, respectively (Table 2).

The relative frequencies of OA-sensitive primary and secondary spermatocytes are given in Fig. 4B. About $80 \%$ of nuclei could be stimulated into diakinesis/metaphase I, II. The number of spermatozoa varied substantially between males (Fig. 4B). Spermatogonial mitoses were encountered in low numbers.

Fig. 4. Histograms per control patient and average for leptotene, zygotene, pachytene frequencies (IF, A), and the frequencies of primary (M1) and secondary (M2) spermatocytes with contracted chromosomes after OA stimulation (B). The presence of sperm heads is given as a reference. (C, D) The same for patients with obstructive azoospermia (7-11) and non-obstructive azoospermia $(12,13)$.
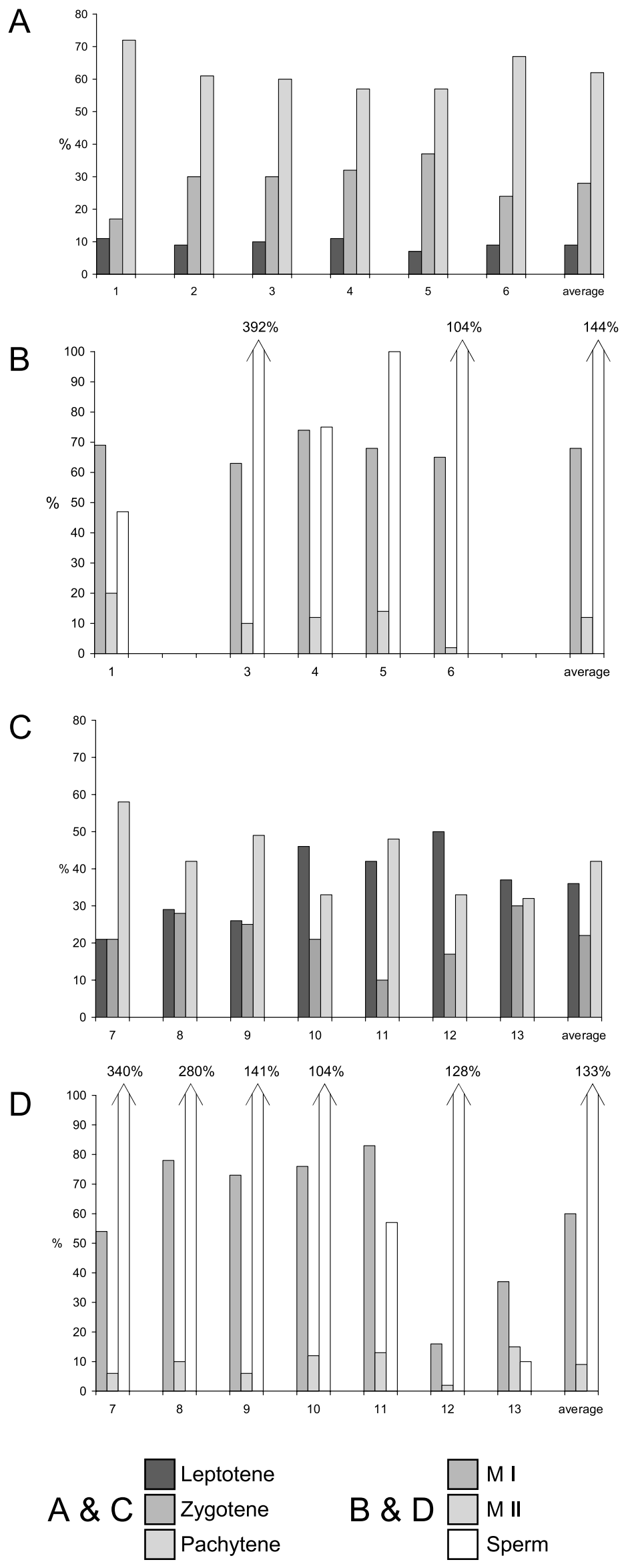
Table 3. Summary of the major findings in the five non-obstructive azoospermic patients from Class III

\begin{tabular}{|c|c|c|c|c|c|c|c|}
\hline No. & $\begin{array}{l}\text { Johnsen } \\
\text { score }\end{array}$ & $\begin{array}{l}\text { Abnormal endocrine } \\
\text { parameters }\end{array}$ & $\begin{array}{l}\text { Testicular } \\
\text { volume }(\mathrm{ml})\end{array}$ & $\begin{array}{l}\text { Histological variation of tubular cross } \\
\text { sections } \mathrm{s}^{\mathrm{a}}\end{array}$ & Meiotic prophase staging & OA stimulation & Sperm \\
\hline 12 & $3.1 / 3.8$ & low testosterone & normal & $\begin{array}{l}32 \% \text { SOS } \\
61 \% \text { variably interrupted } \\
7 \% \text { normal }\end{array}$ & vast excess of leptotene & very poor & present \\
\hline 13 & $4.5 / 4.7$ & low testosterone & normal & $\begin{array}{l}95 \% \text { interrupted at first meiotic prophase } \\
5 \% \text { normal }\end{array}$ & $\begin{array}{l}\text { excess of leptotene, } \\
\text { decrease of pachytene }\end{array}$ & poor & present \\
\hline 14 & $2.0 / 2.0$ & $\begin{array}{l}\text { elevated FSH } \\
\text { low testosterone }\end{array}$ & small (15.5) & $100 \%$ SOS & $\begin{array}{l}\text { some leptotene and zygotene, } \\
\text { no pachytene }\end{array}$ & absent & absent \\
\hline 15 & $3.7 / 2.0$ & $\begin{array}{l}\text { elevated FSH, LH } \\
\text { low testosterone }\end{array}$ & small (14) & $\begin{array}{l}\text { one side } 100 \% \text { SOS, } \\
\text { other side } 69 \% \text { SOS }\end{array}$ & $\begin{array}{l}\text { excess of leptotene, } \\
\text { some zygotene and pachytene }\end{array}$ & $\begin{array}{l}\text { normal, but only } \\
17 \text { cells recovered }\end{array}$ & $\begin{array}{l}\text { late elongating } \\
\text { spermatids }\end{array}$ \\
\hline 16 & $3.5 / 3.3$ & elevated FSH & small (18) & $\begin{array}{l}11 \% \text { variably interrupted } \\
20 \% \text { normal } \\
\text { spermatogonial block and } \\
\text { spermatocyte block }\end{array}$ & uniform arrest at leptotene & absent & absent \\
\hline
\end{tabular}

SOS: Sertoli cell only syndrome.

Class II: Obstructive azoospermic/severely oligozoospermic males ( $n=5$, males $7-11)$. Anatomical examination of males 7 and 8 indicated bilateral absence of the vas deferens as the explanation for the azoospermia. DNA analysis of the CFTR gene showed that both males are heterozygous for a mutant allele (A455E and $\Delta \mathrm{F} 508$, respectively). In male $8,9 \%$ of tubular cross sections had a Johnsen score below 8 (i.e. no spermatozoa present). In both males, leptotene/zygotene ratios were increased, whereas in male 8 , also the zygotene/pachytene ratio was increased (Fig. 4C). OA stimulation was normal and, in concordance with the Johnsen score, both biopsies contained numerous spermatozoa (Fig. 4D).

Patient 9 was azoospermic due to a previous bilateral epididymitis. In patients 10 and 11 a blockade of the epididymis is the most likely explanation of the infertility. Johnsen scores were normal except for a spot of Sertoli cell only syndrome in one testis of patient 10 . This man also presented with a low testosterone level. Patient 11 had earlier been diagnosed with OAT, with two sperm counts being 3.5 and $4.5 \times 10^{6} / \mathrm{ml}$, respectively. The vasogram was normal. This patient had late unilateral testis descent, testicular volumes in the lower range (14 ml left and right) and elevated LH and FSH levels (Table 1). All three patients contained too many leptotene spermatocytes (Fig. 4C). However, OA stimulation gave normal results in all three males (Fig. 4D).

Class III: Non-obstructive azoospermic males $(n=5$, males 12-16). A survey of findings is presented in Table 3. At anatomical evaluation, all parameters were found to be normal. All stages of first meiotic prophase were present in males 12 and 13. Johnsen scores were low, however. FSH and LH concentrations were normal, but testosterone levels were below normal (Table 1). In patient 12, 32\% of cross sections were Sertoli cell only (score 2), 37\% of tubular cross sections only contained spermatogonia (score 3) and 14\% contained spermatogonia with few primary spermatocytes (score 4 ). In patient $13,89 \%$ of cross sections were scored 4-5, i.e. with a few to normal numbers of primary spermatocytes. In both males, normal tubular cross sections with scores $8-10$ were seen, albeit at a frequency of around $6 \%$. In male 12 a vast excess of leptotene stages was found. Also in male 13 the leptotene/zygotene and zygotene/ pachytene ratios are abnormal, with leptotene, zygotene and pachytene each occurring at about the same frequency. In both male 12 and 13, few pachytene spermatocytes can be OA-stimulated (Fig. 4D). This finding agrees with the histological pattern, indicating little efficiency of first meiotic prophase, male 12 being especially poor. However, in agreement with the Johnsen scores, sperm was found in the OA cultures.

Males 14, 15 and 16 showed low Johnsen scores, a high FSH level, and there was an elevated LH level in male 15 as well (Table 1). Also, testosterone concentrations were low in males 14 and 15. Patient 14 had Sertoli cell only syndrome by the Johnsen score, in agreement with a small testicular volume $(15.5 \mathrm{ml})$. No spermatogenic cells were found in the OA culture. In the fibrin-encapsulated cell sample, some leptotene and zygotene primary spermatocytes were encountered, but pachytene stages were absent. Patient 15 was judged to have Sertoli cell only syndrome in one testis on the basis of histology. In the other testis, Sertoli cell only syndrome prevailed (69\%). The remaining other tubular cross sections showed spermatogenesis of variable quality (scores 5-10). These findings were confirmed in the OA assay, showing normal stimulation $(70 \%$, although with only 17 cells recovered). Late elongating spermatids were relatively abundant. In the fibrin clots, only few cells showed staining of SYCP3, most of them with a block at leptotene. However, some zygotene and early pachytene nuclei were seen. Patient 16 had a testis volume in the lower range $(18 \mathrm{ml})$ and his tubuli contained 3\% stage 2, 57\% stage 3, 36\% stage 4 and $4 \%$ stage 5 tubuli (Johnsen score 3.4; see Table 1). Only four spermatocytes showing staining with the anti-SYCP3 antibody could be found in the fibrin clots. These cells were all arrested at leptotene, with complete axial elements, which is unusual. No SC formation was observed. Two spread leptotene spermatocytes from this patient are shown in Fig. 5. No pachytene spermatocytes were scored after OA stimulation. Patient 16 was the only infertile male who mentioned consanguinity in his family. His grandmothers are second cousins. 
Fig. 5. (A, B) Aberrant leptotene nuclei with fully developed axial elements in patient 16 after staining with serum 175 on sedimented nuclei. The arrow in $\mathbf{B}$ points at interaction between axial elements. The bar represents $6 \mu \mathrm{m}$.
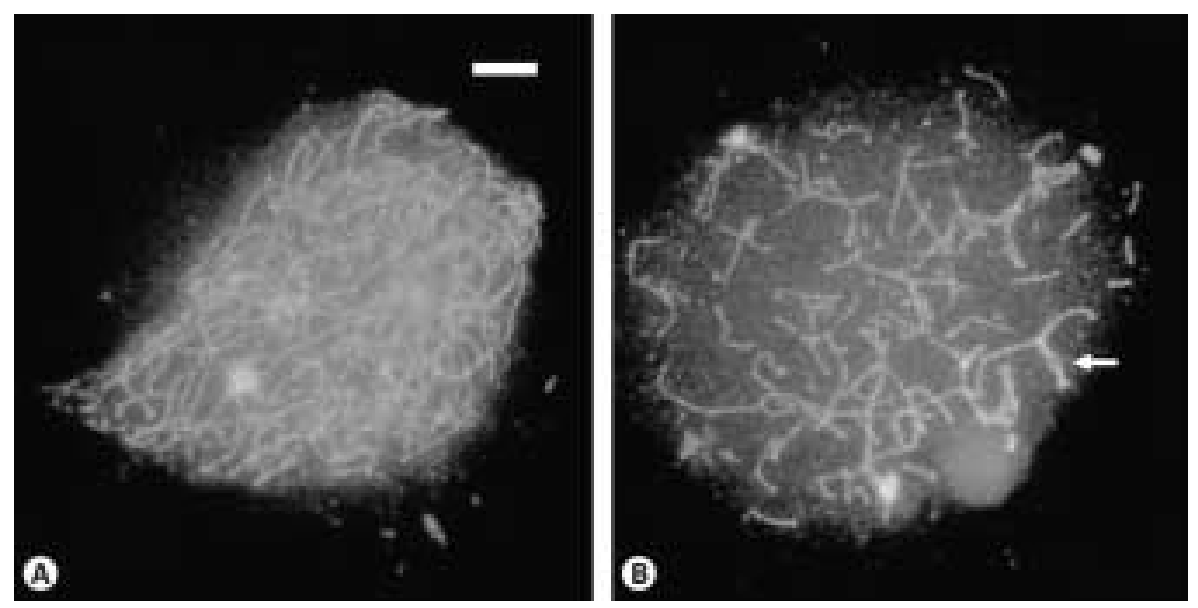

\section{Discussion}

Validation of meiotic prophase (sub)staging in fertile males by immunofluorescence

Antibodies raised against components of the SC have been used before in the analysis of meiosis in infertile male patients. For example, Pousette et al. (1997) used anti-SCP1 and Metzler-Guillemain et al. (2000) used anti-SCP1 and anti-SCP-3. However, if only these antibodies are used, asynaptic pachytene spermatocytes cannot be separated from late zygotene and early diplotene stages. As shown here, the use of anti-ATR avoids mid-late zygotene spermatocytes to be mistaken for pachytene spermatocytes with incomplete SC formation. In mouse zygotene nuclei, Atr is not yet present at the unpaired axial elements of the sex chromosomes (Baart et al., 2000). In addition, in the patients studied here we only rarely observed spermatocytes with mainly "pachytene-like" synaptonemal complexes accompanied by unpaired chromosome segments that can be highlighted with anti-ATR (Fig. 3B, E).

In the series of six control males of proven fertility we found that in fibrin-embedded nuclei, the relative durations of leptotene, zygotene and pachytene are 10, 28 and $62 \%$, respectively (Table 2). Diplotene stages as characterized by SCs resolving into repelling axial elements were rarely seen in control males (an example is shown in Fig. 2G). In these males, early pachytene spermatocytes had a frequency of $33 \%$ (compared to 28 $38 \%$ stage I, II pachytenes; see Solari, 1980; Chandley et al., 1984; Speed and Chandley, 1990), mid pachytene spermatocytes were found at $7 \%$ (ibid. stage III: 6-20\%) and late pachytene spermatocytes at $60 \%$ (ibid. stage IV, V: $44-53 \%$ ). The overall fit of IF with electron microscopy data is good. The differences between mid and late pachytene are due to observer subjectivity at the boundary of these stages, or there may be a slight difference between spreading and whole mounts as used here. We conclude that the analysis of first meiotic prophase in human primary spermatocytes by IF using anti-SYCP 3 and anti-ATR is reliable. When the relative durations of leptotene, zygotene and pachytene in control human males are compared to those in the mouse using the same method (IF on fibrinembedded spermatocytes), zygotene seems to take longer in the human at the expense of pachytene (mouse frequencies of leptotene, zygotene and pachytene are 11,17 and $72 \%$, respectively; Baart et al., 2000).

In the literature, both Lange et al. (1997) and Vendrell et al. (1999) have found a relation between SC abnormalities and male infertility by finding those in 17.5 and $50 \%$ of patients, respectively. We may have missed these patients, or alternatively in these studies, zygotene could have been misinterpreted as asynaptic pachytene with or without breaking SCs.

\section{Validation of the combined investigations in azoospermic males}

Generally, no gross discrepancies were observed between anatomy, endocrine parameters, presence of CFTR-gene mutations, Johnsen score, meiotic prophase substaging by IF and the functional late pachytene stimulation by OA. For example, in the non-obstructive azoospermic males (Class III), the reduced meiotic efficiency by IF and OA score agreed with the low Johnsen scores and the underlying histological patterns (see Tables 1 and 3).

In the obstructive and non-obstructive azoospermic males 7 to 13 , we found a tendency for the leptotene stage to be increased. Especially for obstructive azoospermia, the biological explanation of this finding is not clear. Some males (notably 8,10 and 13) had a lower pachytene to zygotene ratio as well. We also found in the obstructive azoospermics that late zygotene stages were more abundant within zygotene as a class (Table 2).

Thus in obstructive azoospermia, the succession of meiotic prophase substages is not entirely normal. However, in males $7-11$, presenting with obstructive azoospermia, there is an efficient progression of spermatocytes through the meiotic divisions, as indicated by the normal subdivision in pachytene substages (Table 2), the normal fraction of spermatocytes stimulated by $\mathrm{OA}$ and presence of sperm heads in the testicular cell suspension (Fig. 4D). These data are consistent with a correspondingly high Johnsen score in these males (Table 1).

In the oligozoospermic male 11, who has a sperm count of $4 \times 10^{6} / \mathrm{ml}$, the block in the efferent ducts must be partial. Partial obstruction and epididymal dysfunction are not uncom- 
Table 4. Overview of defects in meiotic prophase in the azoospermic patient 16 and male-sterile knock-out mice

\begin{tabular}{|c|c|c|c|c|c|c|}
\hline & Male 16 & Spo11 ${ }^{-1-}$ & $M \operatorname{sh} 4^{--}$and $M \operatorname{sh} 5^{-1}$ & $D m c 1^{-/}$ & Morc $^{-/-}$ & $\mathrm{Mei}^{-/-}$ \\
\hline References & this work & $\begin{array}{l}\text { Baudat et al. (2000) } \\
\text { Mahadevaiah et al. (2001) } \\
\text { Romanienko and Camerini- } \\
\text { Otero }(2000)\end{array}$ & $\begin{array}{l}\text { de Vries et al. (1999) } \\
\text { Kneitz et al. (2000) } \\
\text { Mahadevaiah et al. (2001) } \\
\text { Edelmann et al. (1999) }\end{array}$ & $\begin{array}{l}\text { Pittman et al. (1998) } \\
\text { Yoshida et al. (1998) }\end{array}$ & $\begin{array}{l}\text { Watson et al. } \\
\text { (1998) }\end{array}$ & Libby et al. (2002) \\
\hline Testicular volume & $75 \%$ of normal & $20-30 \%$ of wildtype & $30 \%$ of wildtype & $30 \%$ of wildtype & $<30 \%$ of wildtype & "small" \\
\hline Stage of arrest & spermatogonia/leptotene & leptotene/zygotene & leptotene/zygotene & leptotene/zygotene & leptotene/zygotene & leptotene/zygotene \\
\hline $\begin{array}{l}\text { Clearance from } \\
\text { germinal epithelium }\end{array}$ & not conspicuous & stage IV & stage IV & $\begin{array}{l}\text { stage IV } \\
\text { (by assumption) }\end{array}$ & $\begin{array}{l}\text { stage IV } \\
\text { (by assumption) }\end{array}$ & $\begin{array}{l}\text { stage IV } \\
\text { (by assumption) }\end{array}$ \\
\hline $\begin{array}{l}\text { Complete axial } \\
\text { element formation }\end{array}$ & yes & yes & yes & yes & yes & yes \\
\hline SC formation & always absent & often absent & often absent & often absent & often absent & often absent \\
\hline Recombination & absent & absent & exceptional $^{\mathrm{a}}$ & n.d. ${ }^{b}$ & n.d. & absent \\
\hline $\begin{array}{ll}\text { a } & \text { Personal observa } \\
\text { b } & \text { n.d. }=\text { not determ }\end{array}$ & P. de Boer. & & & & & \\
\hline
\end{tabular}

mon in severely oligozoospermic males with a high Johnsen score (Dohle et al., 2003). We conclude that the results from our detailed studies of meiosis never were discordant with the Johnsen score.

\section{The use of combined investigations in characterizing the mosaic performance of spermatogenesis in cases of non-obstructive azoospermia}

More than half of the non-obstructive azoospermic males have minute foci of normal spermatogenesis, often limited to a few seminiferous tubules (Tournaye et al., 1996; Silber et al., 1997; Turek et al., 1999). This phenomenon was termed "germinal cell aplasia and focal spermatogenesis" by Levin (1979). In the five non-obstructive azoospermic males presented here, there is no systematic maturation arrest, as defined by the inability of the germ line to cross a distinct stage of development (Levin, 1979). These infertile males are more adequately described as mosaics in the quantity/quality of spermatogenesis at the histological level, cytological level, or both. Examples are males 12 and 13 who present with fewer primary spermatocyte contraction stages after OA incubation. As the relative contribution of stage III late pachytene spermatocytes among all spermatocytes is normal (50\% vs. $60 \%$ in controls, Table 2), we assume that the spermatocytes that are not stimulation-competent vanish rapidly from the epithelium. Thus, only part of the pachytene spermatocyte population of these males is competent to enter meiotic division. Male 12, furthermore, contains $32 \%$ tubules with spermatogonia only (score 3 ) or spermatogonia with few spermatocytes $(14 \%$, score 4$)$. Therefore, we can describe male 12 as a histological mosaic at the gonial level and a cytological mosaic at the level of functional meiosis. In male 13, most tubules do show a few (score 4) to normal numbers of primary spermatocytes (score 5). We describe this male as a cytological mosaic for the mid pachytene spermatocyte population (in the mouse, OA stimulates pachytene from the mid to late transition at stage IV, V of the seminiferous epithelium on; Cobb et al., 1999; de Vries et al., 1999). Male 14, who is Sertoli cell only at the histological level (score 2), is mosaic at the cyto- logical level, as some leptotene and zygotene spermatocytes were seen in the fibrin clots. Male 15 is (albeit in one testis only) a mosaic both at the histological and cytological level, showing both tubules without germ cells (score 2), tubules with interrupted spermatogenesis (score 5-7) and even tubules with spermatozoa (scores 8-10). Also male 16 must be a mosaic, as few leptotene spermatocytes were found after immunostaining, and $56 \%$ of tubules were scored as 3 (spermatogonia only). Thus, spermatogonia of this patient are not uniformly competent to reach meiotic prophase, and the spermatocytes that engage into axial element formation do not reach the zygotene stage.

\section{The value of the combined investigation protocol for establishing a parallel between sterile spermatogenic phenotypes in mouse and man}

There is very limited knowledge about the genetic basis of meiotic defects in male patients suffering from non-obstructive azoospermia. We assume, however, that underlying mutations have an autosomal recessive mode of inheritance (Hackstein et al., 2000), as in some cases it has been documented that males suffering from meiotic irregularities are the offspring of consanguineous unions (e.g. Hultén et al., 1970). This view is also supported by recent studies on knock-out mice carrying welldefined, autosomal recessive mutations that cause male-sterile phenotypes associated with meiotic abnormalities (for reviews see Escalier, 2001 and Cooke and Saunders, 2002; Table 4). A human male-sterile example of these with homozygosity for a MSH4 mutation has now been found (Mandon-Pepin et al., 2002)

Two types of male-sterile meiotic phenotypes with an underlying genetic basis can be distinguished in the mouse. The first type is characterized by massive apoptosis at the time of the pachytene checkpoint, at the junction between mid and late pachytene during stage IV of the cycle of the seminiferous epithelium (de Vries et al., 1999). Mostly, male-sterile mice showing this phenotype have been ablated for gene products involved in homologous recombination (or assumed to be so). Generally, the great majority of primary spermatocytes show 
extended axial element formation without synapsis. Examples are the knock-out mouse models for Spo11, Msh4, Msh5 and Dmcl, the EMS-induced meil and the spontaneously arisen morc autosomal recessive mutations (see Table 4). In the second type of male-sterile phenotypes, primary spermatocytes start to succumb at or after the pachytene checkpoint, with apoptosis continuing during the late pachytene stage and peaking during diakinesis/metaphase I. Usually, some spermatocytes manage to complete meiosis after which oligoteratospermiogenesis follows. Examples of this phenotype are the Pms2 knock-out mouse (Baker et al., 1995) and many of the reciprocal translocations that lead to male sterility (de Boer et al., 1986).

It appears that none of the five non-obstructive, azoospermic males described here completely resembles one of these knock-out mouse models. The main reason for this discrepancy is that all males show a much higher level of histological variance between the seminiferous tubules compared to the mouse, where the histological pattern usually is consistent with a singular meiotic block. Male 13 resembles the second type of malesterile meiotic mutants, but without meiotic synaptic difficulties being involved. Male 16 resembles the first type of malesterile mutants with extensive axial element formation without synapsis, but only for those spermatogonia that are able to develop into primary spermatocytes. The fact that the grandmothers are second cousins suggests that the phenotype is caused by an autosomal recessive mutation.

Arguments for an environmental origin of the functional mosaicism can equally be found, endocrine disruptors being candidates for an in utero effect in development of the seminiferous epithelium (see Damgaard et al., 2002 for a recent review). Histological evidence for a mosaic performance of spermatogenesis in the contralateral testis of patients with unilateral testicular germ cell cancer, caused as proposed by endocrine disruptors, has recently been produced (Hoei-Hansen et al., 2003).

\section{Concluding remarks}

The detailed investigation of meiotic prophase in a limited clinical series of male patients with idiopathic azoospermia allows two general conclusions to be drawn. First, it is difficult to compare the meiotic phenotypes of infertile males to those of knock-out mouse mutants because in man, different seminiferous tubules display extensive variation in the performance of meiosis, possibly extending into one cross-section. This is not the case in the mouse. Second, when comparing meiotic phenotypes in mouse and man, it should be kept in mind that orthologous mutant genotypes may lead to meiotic phenotypes that are only partially comparable. In that respect, the mosaic character of azoospermia in the human as shown here likely is a factor that hinders a direct comparison of orthologous genetic phenotypes between mouse and man. Functional spermatogenic mosaicism as analyzed in this study, is only revealed when phenotyping is achieved by a combination of methods. Also, differences between mouse and man may exist in the controlled environment mouse mutants are kept in, this contrasting to the situation in man, where a debate about disturbing factors in the pre- and postnatal genesis of a functionally uniform epithelium is continuing (Damgaard et al., 2002).

\section{Acknowledgements}

We thank Frits van der Hoeven and Christa Heyting, Department of Genetics, Wageningen University, for technical assistance and the generous supply of anti-SYCP3 respectively, Kathleen Keegan, ICOS Seattle, for donating anti-Atr antibody, and Rien Blankenstein and George Posthuma of the University Medical Center Utrecht for determining hormone levels and help with confocal microscopy, respectively.

\section{References}

Baart EB, de Rooij DG, Keegan KS, de Boer P: Distribution of Atr protein in primary spermatocytes of a mouse chromosomal mutant: A comparison of preparation techniques. Chromosoma 109:139_ 147 (2000).

Baker SM, Bronner CE, Zhang L, Plug AW, Robatzek M, Warren G, Elliott EA, Yu J, Ashley T, Arnheim N, Flavell RA, Liskay RM: Male mice defective in the DNA mismatch repair gene PMS2 exhibit abnormal chromosome synapsis in meiosis. Cell 82:309-319 (1995).

Baudat F, Manova K, Yuen JP, Jasin M, Keeney S: Chromosome synapsis defects and sexually dimorphic meiotic progression in mice lacking Spol1. Mol Cell 6:989-998 (2000).

de Boer P, Searle AG, van der Hoeven FA, de Rooij DG, Beechey CV: Male pachytene pairing in single and double translocation heterozygotes and spermatogenic impairment in the mouse. Chromosoma 93:326-336 (1986).

de Braekeleer M, Dao N-T: Cytogenetic studies in male infertility: a review. Hum Reprod 6:245-250 (1991).
Chandley AC, Fletcher JM: Centromere staining at meiosis in man. Humangenetik 18:247-252 (1973).

Chandley AC, Goetz P, Hargreave TB, Joseph AM, Speed RM: On the nature and extent of XY pairing at meiotic prophase in man. Cytogenet Cell Genet 38:241-247 (1984).

Cobb J, Cargile B, Handel MA: Acquisition of competence to condense metaphase I chromosomes during spermatogenesis. Dev Biol 205:49-64 (1999).

Cooke HJ, Saunders PT: Mouse models of male infertility. Nat Rev Genet 3:790-801 (2002).

Damgaard IN, Main KM, Toppari J, Skakkebaek NE: Impact of exposure to endocrine disruptors in utero and in childhood on adult reproduction. Best Pract Res Clin Endocrinol Metab 16:289-309 (2002).

Dohle GR, van Roijen HJ, Pierik FH, Vreeburg JT, Weber RF: Subtotal obstruction of the male reproductive tract. Urol Res 31:2-24 (2003).

Edelman W, Cohen PE, Kneitz B, Winand N, Lia M, Heyer J, Kolodner R, Pollard JW, Kucherlapati R: Mammalian MutS homologue 5 is required for chromosome pairing in meiosis. Nat Genet 21: 123-127 (1999).
Eggerding FA, Ivannisci AM, Brinson E, Grossman P, Winn-Deen ES: Fluorescence-Based Oligonucleotide Ligation assay for analysis of cystic fibrosis transmembrane conductance regulator gene mutations. Hum Mutat 5:153-165 (1995).

Escalier D: Impact of genetic engineering on the understanding of spermatogenesis. Hum Reprod Update 7:191-210 (2001).

ESHRE Capri Workshop, European Society for Human Reproduction and Embryology. Infertility revisited: the state of the art today and tomorrow. Hum Reprod 11:1779-1807 (1996).

Evans EP, Breckon C, Ford CE: An air-drying method for meiotic preparations from mammalian testis. Cytogenetics 3:289-294 (1964).

Hackstein JHP, Hochstenbach R, Pearson PL: Towards an understanding of the genetics of human male infertility: lessons from flies. Trends Genet 16:565-572 (2000)

Hilscher W: Some remarks on the female and male keimbahn in the light of evolution and history. J Exp Zool 285:197-214 (1999). 
Hoei-Hansen CE, Holm M, Rajpert-De Meyts E, Skakkebaek NE: Histological evidence of testicular dysgenesis in contralateral biopsies from 218 patients with testicular germ cell cancer. J Pathol 200:370 374 (2003).

Hull MG, Glazener CM, Kelly NJ, Conway DI, Foster PA, Hinton RA, Coulson C, Lambert PA, Watt EM, Desai KM: Population study of causes, treatment and outcome of infertility. $\mathrm{Br}$ Med J 291:1693-1697 (1985).

Hultén M: Chiasma distribution at diakinesis in the normal human male. Hereditas 76:55-78 (1974).

Hultén M, Eliasson R, Tillinger KG: Low chiasma count and other meiotic irregularities in two infertile $46 \mathrm{XY}$ men with spermatogenic arrest. Hereditas 65:285-290 (1970).

Hunt PA, LeMaire R, Embury P, Mroz K, Sheean L: Analysis of chromosome behavior in intact mammalian oocytes: monitoring the segregation of a univalent chromosome during mammalian female meiosis. Hum Mol Genet 4:2007-2012 (1995).

Johnsen SG: Testicular biopsy score count - A method for registration of spermatogenesis in human testes: normal values and results in 335 hypogonadal males. Hormones 1:2-25 (1970).

Keegan KS, Holtzman DA, Plug AW, Christenson ER, Brainerd EE, Flaggs G, Bentley NJ, Taylor EM, Meyn MS, Moss SB, Carr AM, Ashley T, Hoekstra MF: The Atr and Atm protein kinases associate with different sites along meiotically pairing chromosomes. Genes Dev 10:2423-2437 (1996).

Kneitz B, Cohen PE, Avdievich E, Zhu L, Kane MF, Hou H Jr, Kolodner RD, Kucherlapati R, Pollard JW, EdelmannW: MutS homolog 4 localization to meiotic chromosomes is required for chromosome pairing during meiosis in male and female mice. Genes Dev 14:1085-1097 (2000).

Krausz C, Quintana-Murci L, McElreavey K: Prognostic value of $Y$ deletion analysis: what is the clinical prognostic value of $\mathrm{Y}$ chromosome microdeletion analysis. Hum Reprod 15:1431-1434 (2000).

Kremer JAM, Tuerlings JHAM, Meuleman EJH, Schouten F, Mariman E, Smeets DFCM, Hoefsloot LH, Braat DDM, Merkus HMWM: Microdeletions of the Y chromosome and cytoplasmic sperm injection (ICSI): from gene to clinic. Hum Reprod 12:687-691 (1997)

Lange R, Krause W, Engel W: Analysis of meiotic chromosomes in testicular biopsies of infertile patients. Hum Reprod 12:2154-2158 (1997).

Levin HS: Testicular biopsy in the study of male infertility, its current usefulness, histological techniques and prospects for the future. Hum Pathol 10:569_ 584 (1979).

Libby BY, De La Fuente R, O’Brien MJ, Wigglesworth K, Cobb J, Inselman A, Eaker S, Handel MA Eppig JJ, Schimenti JC: The mouse meiotic mutation meil disrupts chromosome synapsis with sexually dimorphic consequences for meiotic progression. Dev Biol 242:174-187 (2002).
Lilford R, Jones AM, Biship DT, Thornton J, Mueller $\mathrm{R}$ : Case-control study of whether infertility in men is familial. Br Med J 309:570-573 (1994).

Mahadevaiah SK, Turner JMA, Baudat F, Rogakou EP, de Boer P, Blanco-Rodriguez J, Jasin M, Keeney S, Bonner WM, Burgoyne PS: Recombinational DNA double-strand breaks in mice precede synapsis. Nat Genet 27:271-276 (2001).

Mandon-Pepin B, Derbois C, Matsuda F, Cotinot C, Wolgemuth DJ, Smith K, McElreavey K, Nicolas A, Fellous M: Human infertility: meiotic genes as potential candidates. Gynecol Obstet Fertil 30: 817-821 (2002)

Meschede D, Lemcke B, Behre HM, de Geyter CH, Nieschlag E, Horst J: Clustering of male infertility in the families of couples treated with intracytoplasmic sperm injection. Hum Reprod 15:16041608 (2000).

Metzler-Guillemain C, Guichaoua M-R: A simple and reliable method for meiotic studies on testicular samples used for intracytoplasmic sperm injection. Fertil Steril 74:916-919 (2000).

Moens PB, Tarsounas M, Morita T, Habu T, Rottinghaus ST, Freire R, Jackson SP, Barlow C, Wynshaw-Boris A: The association of ATR protein with mouse meiotic chromosome cores. Chromosoma 108:95-102 (1999).

O'Brien DA: Stage-specific protein synthesis by isolated spermatogenic cells throughout meiosis and early spermatogenesis in the mouse. Biol Reprod 37:147-157 (1987).

Offenberg HH, Dietrich AJJ, Heyting C: Tissue distribution of two major components of synaptonemal complexes of the rat. Chromosoma 101:83-91 (1991).

Peters AHFM, Plug AW, van Vugt M, de Boer P: A drying down technique for spreading of mammalian meiocytes from the male and female germline. Chromosome Res 5:66-68 (1997).

Pittman DL, Cobb J, Shimenti KJ, Wilson DM, Cooper E, Brignull E, Handel MA, Shimenti JC: Meiotic prophase arrest with failure of chromosome synapsis in mice deficient for $\mathrm{Dmcl}$, a germline-specific RecA homolog. Mol Cell 1:697-705 (1998).

Pousette A, Leijonhufvud P, Arver S, Kvist U, Pelttari J, Höög C: Presence of synaptonemal complex protein 1 transversal filament-like protein in human primary spermatocytes. Hum Reprod 12:24142417 (1997).

Romanienko PJ, Camerini-Otero RD: The mouse Spol1 gene is required for meiotic chromosome synapsis. Mol Cell 6:975-987 (2000).

Silber SJ: Intracytoplasmic sperm injection today: a personal review. Hum Reprod 13, Suppl 1:208218 (1998).

Silber SJ, Nagy Z, Devroey P, Tournaye H, Van Steirteghem AC: Distribution of spermatogenesis in the testicles of azoospermic men: the presence or absence of spermatids in the testes of men with germinal failure. Hum Reprod 12:2422-2428 (1997).
Solari AJ: Synaptonemal complexes and associated structures in microspread human spermatocytes. Chromosoma 81:315-337 (1980).

Speed RM, Chandley AC: Prophase of meiosis in human spermatocytes analysed by EM microspreading in infertile men and their controls and comparison with human oocytes. Hum Genet 84:547-554 (1990).

Tournaye H, Liu J, Nagy PZ, Camus M, Goossens A, Silber S, van Steirteghem AC, Devroey P: Correlation between testicular histology and outcome after intracytoplasmic sperm injection using testicular spermatozoa. Hum Reprod 11:127-132 (1996).

Tuerlings JH, de France HF, Hamers A, Hordijk R, van Hemel JO, Hansson K, Hoovers JM, Madan K, van der Blij-Philipsen M, Gerssen-Schoorl KB, Kremer JA, Smeets DF: Chromosomes studies in 1792 males prior to intracytoplasmic sperm injection: the Dutch experience. Eur J Hum Genet 6:194-200 (1998).

Tung K-S, Hong E-J, Roeder GS: The pachytene checkpoint prevents accumulation and phosphorylation of the meiosis-specific transcription factor $\mathrm{Ndt} 80$ Proc Natl Acad Sci USA 97:12187-12192 (2000).

Turek PJ, Givens CR, Schriock ED, Meng MV, Pedersen RA, Conaghan J: Testis sperm extraction and intracytoplasmic sperm injection guided by prior fine-needle aspiration mapping in patients with nonobstructive azoospermia. Fertil Steril 71:552557 (1999).

Vendrell JM, Garcia F, Veiga A, Calderon G, Egozcue S, Egozcue J, Barri PN: Meiotic abnormalities and spermatogenic parameters in severe oligoasthenozoospermia. Hum Reprod 14:375-378 (1999).

de Vries SS, Baart EB, Dekker M, Siezen A, de Rooij DG, de Boer P, te Riele H: Mouse MutS-like protein Msh5 is required for proper chromosome synapsis in male and female meiosis. Genes Dev 13:523-531 (1999).

Watson ML, Zinn AR, Inoue N, Hess KD, Cobb J, Handel MA, Halaban R, Duchene CC, Albright GM, Moreadith RW: Identification of morc (microrchidia), a mutation that results in arrest of spermatogenesis at an early meiotic stage in the mouse. Proc Natl Acad Sci USA 95:14361-14366 (1998).

Westlander G, Hamberger L, Hanson CV, Lundin K, Nilsson L, Söderland B, Werner C, Bergh C: Diagnostic epididymal and testicular sperm recovery and genetic aspects in azoospermic men. Hum Reprod 14:118-122 (1999).

Wiltshire T, Park C, Caldwell KA, Handel MA: Induced premature G2/M-phase transition in pachytene spermatocytes includes events unique to meiosis. Dev Biol 169:557-567 (1995).

Yoshida K, Kondoh G, Matsuda Y, Habu T, Nishimune Y, Morita T: The mouse RecA-like gene Dmcl is required for homologous chromosome synapsis during meiosis. Mol Cell 1:707-718 (1998). 